\title{
KULTUURORGANISASIES BINNE BEPAALDE BEROEPSGROEPE
}

Daar bestaan in Suid-Afrika ' $n$ aantal kultuurverenigings wat hulle lede uitsluitlik of hoofsaaklik uit die personeel van 'n bepaalde beroepsgroep trek, naamlik die Afrikaanse Taalen Kultuurvereniging (Suid-Afrikaanse Spoorweë en Hawens), afgekort tot A.T.K.V. (S.A.S. en H.), die Afrikaanse Taal- en Kultuurbond (Pos- en Telegraafwese), (A.T.K.B. (P. en T.)), die Afrikaanse Kultuurvereniging van die Suid-Afrikaanse Polisie (Akpol) en die Afrikaanse Kultuurvereniging van die Weermag (A.K.V.V.).

Dat mense wat in dieselfde beroep staan of in ' $n$ bepaalde beroepsverband werksaam is in hulle dagtaak, organisasies in die lewe roep om hulle materiële belange te bevorder, d.w.s. belange wat gaan oor diensvoorwaardes en voorregte, en ook organisasies wat daarop ingestel is om die besondere beroep te bestudeer, is algemeen bekend en reeds vir baie jare aanvaar. Dit tref ons aan in vakunies, personeelverenigings, institute, akademies ens. Maar die bestaan van 'n kultuurvereniging binne beroepsverband is vir die oningewyde ietwat vreemd, soseer dat prof. Abel Coetzee meedeel dat ons stamgenootlike tydgenote in Europa verbaas na die rede hiervoor vra. Hoe bring ons dan die Spoorweë en die Hawens in verband met kultuur? Bestaan daar 'n verband wat dit regverdig?

As ons hierdie vrae wil beantwoord, is dit nodig om bietjie terug te loop op die spoor van die geskiedenis van ons kultuurverenigings in die algemeen en ietwat meer in besonderhede van die van die A.T.K.V., die oudste van die bestaande kultuurverenigings wat in hierdie kategorie val. Nie dat dit nodig beskou word om die bestaan van hierdie verenigings te verdedig nie - die aansienlike mate van welslae wat hulle reeds behaal het, is waarskynlik genoegsame regverdiging vir hulle bestaan.

Dit moet hier duidelik verstaan word dat ons handel met gevestigde, geordende en getalsterk organisasies wat op 'n redelike hegte grondslag oor 'n tydperk bestaan, wat breedopgestelde doelstellings het en nie met kleiner groepe wat vir 'n bepaalde doel in die lewe geroep word nie, soos bv. sang groepe, toneelgroepe e.d.m. wat deur mense wat saam werk 
gestig word en weer ophou om te bestaan sodra die doel bereik is of die groep uitmekaar gaan. Laasgenoemde groepe, wat inderdaad ook kultuurwerk doen, kom vry algemeen voor.

Mense verkies om in groepe op te tree, om hulle saam te snoer in 'n groter verband en so saam te werk. Talle voorbeelde van groepe met allerlei doelwitte, sommige lofwaardig, ander weer, soos misdadigerbendes, met anti-sosiale neigings, bestaan oral. Vrywillige groepvorming is 'n onderwerp wat deur sosioloë bestudeer word en hulle hou hulle besig o.a. met vraagstukke soos die wyse waarop groepe ontstaan, wat hulle invloed is op die indiwidu en hoe die indiwidu weer die groep beïnloed, die doeltreffendheid van groepe, onderlinge skakeling en die plek van die groep in die gemeenskap. Daar is wetenskaplik vasgestel wat ons seker almal weet (of vermoed) dat 'n groep 'n ingrypende invloed op die samelewing uitoefen, dat daar langs die weg van gesamentlike optrede groot welslae behaal kan word en ook dat die groep die houding en optrede van die enkeling in ' $n$ bepaalde rigting kan stuur.

Die Afrikanervolk het gedurende die afgelope eeu 'n groot aantal verenigings en organisasies tot stand gebring. Dié hiervan wat as arbeidsterrein die Afrikaanse taal en kultuur afgebaken het, het beslis 'n merkwaardige bydrae gelewer tot die volkswording van die Afrikaner, tot die bevordering van die Afrikaanse taal en tot die skepping van 'n eic tradisie en leefwyse. Die bydrae van enkelinge was op verskillende terreine onteenseglik groot en waardevol, maar dit is bykans onmoontlik om die geskiedenis van die Afrikanervolk en van die Afrikaanse Taalbeweging te begryp sonder dat gelet word op hierdie organisasies en die werk wat hulle gedoen het.

Toestande in Suid-Afrika teen die einde van die $19 \mathrm{e}$ eeu toe die eerste Afrikaanse taal- en kultuurvereniging, nl. die Genootskap van Regte Afrikaners, gestig is, is oorbekend. Ons hoef nie daarby stil te staan nie en kan maar net daarop let dat Afrikaans toe al meer as honderd jaar gepraat is, maar deur die Engelse owerhede misken is en ook deur baie van ons eie mense as minderwaardig beskou is. Die klompie Afrikaners wat hierdie genootskap op 14 Augustus 1875 gestig het, was besiel met die ideaal „om te staan vir ons Taal, ons Nasie en ons Land". Hulle het gesien dat die voortbestaan van die volk bedreig word en besluit om as groep hulle kragte 
saam te span, hulle mede-Afrikaners te besiel om te veg vir erkenning van hulle moedertaal en ook so aan die Afrikanervolk 'n eie bestaansreg te verseker. Die G.R.A. het dus ontstaan uit die nood van die volk en het 'n militante opset en doelstelling gehad. Hy het veel vermag deur middel van publikasies en die invloed van 'n groeiende ledetal. Hulle was bereid om hard te werk, op te offer en om sonder ophou te veg.

Ná die Genootskap van Regte Afrikaners is ook ander organisasies met soortgelyke agtergrond gestig, soos die BoereBeskermingsvereniging wat ten doel gehad het die saamsnoering van die Boerebevolking om hulle belange te beskerm, daarná die Afrikanerbond, eintlik ook met die doel om Boerebelange te bevorder. Beide hierdie organisasies het ook ekonomiese en politieke doelstellinge gehad. In 1890 word die ZuidAfrikaanse Taalbond in die lewe geroep. Intussen gaan die G.R.A. met sy werksaamhede voort en oefen veral groot invloed uit deur middel van die tydskrif Die Afrikaanse Patriot. Die eintlike motief vir die stigting van die G.R.A. was om die Bybel in Afrikaans te vertaal en die lede se werk was dan ook standhoudend hierop ingestel, alhoewel hulle besluit het om eers ander dinge te doen om die volk daarvoor ontvanklik te maak. In 1889 verskyn dan 'n eerste poging in hierdie rigting toe drie hoofstukke uit Genesis, vertaal deur ds. S. J. $\mathrm{du}$ Toit, in druk verskyn het. Later het egter probleme ont staan, het verdeeldheid ingetree en bring dit die einde van die Patriot en die G.R.A. hier aan die begin van die 20e eeu.

Die Tweede Vryheidsoorlog het die groei van die Afrikanervolk en -taal ' $n$ gevoelige terugslag toegedien en die platgeslane Afrikaner moes weer moeisaam orent kom, sy wonde verbind en weer van vooraf begin bou. Dit was egter nie lank nie voordat wat ons vandag ken as die Tweede Taalbeweging stilweg begin, sy koers kry, sy pas versnel en toe met oortuiging vorentoe beur.

Die eerste jare na die oorlog word gekenmerk deur gespierde optrede en oproepe deur leiers wat al gou die besef laat posvat dat ten einde die stryd doeltreffend aan te knoop, georganiseerde aksie nodig is. Op 13 Desember 1905 word in Pretoria die Afrikaanse Taalgenootskap gestig, wat byna natuurlikerwys weerstand ervaar van die owerhede en ook in eie kamp. Op 3 November 1906 word die Afrikaanse Taalver- 
eniging in Kaapstad gestig. In die Oranje-Vrystaat is ook, ná aanvanklike onsekere optrede, in 1908 'n vereniging "Onze Taal" gestig wat daarna met oortuiging die stryd aangeknoop het.

'n Gebeurtenis wat vir die taalstryd van groot betekenis sou blyk te wees, is die stigting van die Suid-Afrikaanse Akademie vir Taal, Lettere en Kuns op 2 Julie 1909. Totdat die Akademie op die toneel verskyn het, was daar onder Afrikaners self 'n aansienlike mate van verdeeldheid veral oor die keuse tussen Afrikaans en Nederlands. Die Akademie het reeds vroeg in sy bestaan daarin geslaag om duidelikheid in dic strewe te bring en die strydendes te verenig. Alhoewel die Grondwet van die Akademie bepaal het dat die doelstelling sou wees: „De handhaving en bevordering van de Hollandse Taal en Letteren ..." is "Hollands" omskrywe as bedoelende beide Afrikaans en Nederlands. Dit is dan ook nog eers weer 'n paar jaar later dat die Akademie daartoe oorgegaan het om leiding te gee veral op die gebied van die bevordering van Afrikaans. Die Akademie het vervolgens 'n betekenisvolle bydrae tot die bevordering van ons taal gelewer en het spoedig plek verower as die hoogste gesag op o.a. die gebied van die Afrikaanse taal, 'n plek wat hy vandag nog beklee.

Die Akademie was, en is steeds, 'n eksklusiewe organisasie met 'n beperkte ledetal wat dus nie die volk op breë grondslag kon saamsnoer vir optrede nie. Hierdie taak is sedert 1929 deur die Federasie van Afrikaanse Kultuurverenigings onderneem. Studerende jongmense het ook saamgewerk en wel deur middel van die Afrikaanse Studentebond wat in 1916 gestig is met o.a. die doelstelling om die Afrikaanse kultuur te bevorder. Die Voortrekkerbeweging is as jeugbeweging op 30 September 1931 van stapel gestuur met die doel om aan die Afrikaanse kind ook die geleentheid te bied om hom in 'n organisatoriese verband in 'n Afrikaanse atmosfeer uit te lewe.

Soos 'n goue draad loop een kenmerk deur al hierdie genoemde verenigings: hulle is gevestig op Christelik-nasionale grondslag. Die G.R.A. reeds het in sy reglement bepaal dat iedere lid moet glo in die versoeningsdood van onse Heer Jesus Christus. Hierdie grondslag vind ons in meeste van die organisasies wat daarna gestig is en van die wat vandag nog bestaan. 
Tot ongeveer die einde van die $19 \mathrm{e}$ eeu was die Afrikaner hoofsaaklik op die platteland ekonomies en andersins bedrywig as landbouer. Omdat daar tot in daardie stadium baie min nywerheidsbedryf was, het hy 'n belangrike posisie beklee in die ekonomiese lewe van Suid-Afrika. Die ontdekking van diamante en goud en ook ander faktore bring 'n verandering in die ekonomiese struktuur wat die Afrikaner onverhoeds en onvoorbereid oorval. As gevolg hiervan en ander oorsake, word talle van die landelinge van die plase na stede en dorpe gedwing waar hulle 'n heenkome moes soek. Dit het aanleiding gegee tot die ontstaan van 'n ",armblanke-vraagstuk" wat na die Eerste Wêreldoorlog en in die droogte- en depressiejare van 1920-1930 geweldige afmetings aangeneem het. Die Afrikaner wat in betaalde betrekkings opgeneem is, is in nederige posisies geplaas, maar baie het nie eers daardie geleentheid gekry nie. Afrikaners het hulle onder andere na die spoorweë, die polisie en ander afdelings van die Staatsdiens gewend vir 'n heenkome. Veral na 1924 was dit staatsbeleid om die vraagstuk van verarmde blankes die hoof te bied deur werkverskaffing op paaie, dambouskemas, onderstandswerke en die spoorweë.

In hierdie nuwe werksomgewings het die Afrikaner vreemd gevoel, kon hy hom nie handhaaf nie en is sy taal en bestaansreg gering geag. Inderdaad was die opset en samestelling van hierdie arbeidsvelde wat hy betree het, van so 'n aard dat alles om hom anders was as waaraan hy gewoond was en het hy ook vyandiggesindheid teëgekom. Hy was tot dusver 'n landeling. Die handel was in die hande van anderstaliges, die spoorweë is deur die Brit hierheen gebring en was Engels georiënteer en deur Engelssprekende personeel bedryf. Die polisiediens is deur Britse troepe beman en elke ander sektor van die openbare lewe is so vir die Afrikaner gesluit, of waar hy toegelaat is, is hy in ondergeskikte posisies geplaas en moes hy hom aanpas by 'n vreemde omgewing. Op die vooraand van uniewording in 1910 was die persentasie Afrikaners in die Central South African Railways 16.3 en in die Cape Government Railways 9.0. Die Natal Government Railways was $100 \%$ Engelssprekend. Die getal Afrikaanssprekendes in al die spoorwegstelsels was in 1910 slegs $9.8 \%$, hoofsaaklik rangeerders, kondukteurs en klerke. In 1921 was dit $42.4 \%$ en in 1930 nagenoeg $50 \%$. 
Alhoewel die getalsterkte van Afrikaners dus vinnig toegeneem het, was die beherende poste nog in die hande van Engelssprekendes en is Afrikaans tot by die dertigerjare baie min bestaansreg gegun. Afrikaners self het om verskeie redes Engels gepraat en geskryf en genoeë geneem om dokumente, regulasies en opdragte in Engels te ontvang. Die bedryfstaal was Engels en doelbewuste pogings is aangewend om dit so te hou. Senior amptenare was eentalig en ten spyte van die grondwetlike waarborg van taalgelykheid, het daar so iets in die praktyk baie min tereg gekom. Nadat in 1925 Nederlands deur Afrikaans as amptelike taal vervang is, het Afrikaans nog maar weinig vordering gemaak omdat daar o.a. geen vaktaal was nie. Inderdaad kan gesê word dat die spoorweë toe die vertaaltydperk betree het. Alles is in Engels gedoen, en waar nodig (en so min moontlik) is verslae, opdragte, handleidings ens. in Afrikaans vertaal.

In die twintigerjare het daar egter 'n beroering in Afrikanergeledere gekom. Ons jong mense het in groter getalle afgestudeer aan universiteite, hier en oorsee, in onderwyskolleges, en vak- en tegniese skole. Veral die jong Afrikaner, sat en moeg vir miskenning en verkleinering, vat vlam en stap kop omhoog, vorentoe, aangevoer en aangevuur deur digters, skrywers, joernaliste en leiers. Dit is niks anders nie as die besef wat deurbreek dat die Afrikaner self moet arbei aan sy agterstand indien hy as kultuursoort staande sou wou bly. Die Nasionale Party behaal in 1924 gedeeltelik en in 1929 op oortuigender wyse sukses op staatkundige terrein. Die Afrikaner kom tot ontwaking.

Hierdie veggees het ook in die spoorweë kop uitgesteek en die Afrikaanse spoorwegman het begin besef dat hy op homself aangewese is om sy posisie te verbeter. Die mooi leiding en voorbeeld gestel van verskeie manne het bewys dat dit aan yweraars en leiers in spoorweggeledere nie ontbreek nie. Daar het egter 'n diepgevoelde behoefte bestaan aan georganiseerde en eendragtige optrede - 'n begeerte om as groep aktief in te tree en te arbei, om te bou aan die Afrikaner se volkseie.

In Johannesburg is daar teen die einde van die twintigerjare van tyd tot tyd pogings aangewend om 'n eie Afrikaanse vereniging te stig, maar dit wou net nie vlot nie, hoofsaaklik as gevolg van verdeeldheid in eie geledere. In 1930 ontstaan 
daar by 'n spoorwegamptenaar, ene mnr. S. J. van der Spuy, destyds te Kaapstad geplaas, die gedagte om 'n Afrikaanse debatsvereniging te stig met die doel om ,Afrikaans onder ons eie mense te bevorder en terselfdertyd ons Engelse kollegas te help met die praktiese deel". Gesien teen die agtergrond van toestande destyds is die tweede gedeelte van hierdie gestelde voorneme verstaanbaar. Hy het met 'n paar mense gepraat en eendag in die etensuur het hy vier ander Afrikaners gevra om met hom saam te stap na die Tafelbaaise hawe en toe sy plan aan hulle meegedeel. By die standbeeld van Jan van Riebeeck het hulle gaan sit, klaar gepraat en toe besluit om voort te gaan. Eers egter is voelers nog uitgestuur om te bepaal hoe die Spoorwegadministrasie sou staan teenoor so 'n gedagte. Destydse spoorwegminister C. W. Malan het hulle aangemoedig om voort te gaan en so het daar op 19 Augustus 1930 'n twaalftal Afrikaners vergader en die A.T.K.V. (S.A.S. en H.) gestig - let wel, geen debatsvereniging nie, maar ' $n$ taal- en kultuurvereniging. Twee dae later word die eerste openbare vergadering in die Afrikaner-Koffiehuis in Kaapstad gehou, waar 33 persone teenwoordig was. Die voorsitter het die doelstelling van die pasgestigde vereniging verduidelik, nl. die bevordering van Afrikaans binne en buite die spoorwegdiens. 'n Ander lid het die eerste pleidooi om taalhandhawing in A.T.K.V. se geskiedenis gelewer. Hy het lede aangespoor om suiwer Afrikaans te praat en Anglisismes uit hul taal te verban. Hy het Afrikaners geroskam omdat hulle meesal Engels lees en skryf.

Daar was onmiddellik baie bemoedigende reaksie op hierdie stigting. Afrikaners buite die spoorwegdiens het die stigting verwelkom. Die Burger het dit aangeprys en spoorwegmanne self het ingespring, lede gewerf en takke oral in die land gestig. Mens kan slegs met bewondering kyk na die durf, daadkrag en waagmoed van die handjievol stigterslede wat op 'n tydstip toe Afrikaans in die spoorweë in hoë kringe nie verwelkom is nie en toe depressie geheers het, daartoe oorgegaan het om 'n vereniging te stig wat op die ledegeld van een van die swakste besoldigde blanke arbeidsgroepe sou moes staat maak. Hulle kon geen uiterlike vergoeding of materiële voordeel aanbied nie. Hulle kon slegs 'n beroep doen op die Afrikaner om sy eie uit te bou en te handhaaf. Hulle het geen aanmoediging of steun gekry van amptenare in hoë poste nie, 
selfs nie van die enkele Afrikaners wat toentertyd reeds senior betrekkings beklee het nie. Die Taalgenoot skryf kort na die stigting „Ons wag nog tevergeefs op die ontwikkelde Afrikaners om van hulle hoë voetstuk af te daal en 'n helpende hand uit te reik na die klein aantal voorvegters, wat met ondergang in die ongelyke stryd bedreig is, omdat hulle medevolksgenote op die spoorweë tevrede is met die hoë sport wat hulle self op die leer van bevordering bereik het en nie daardie status wil benadeel deur openlik hulle in die taalstryd te meng nie".

Onder sulke omstandighede, soos sy roemryke voorgangers, die G.R.A., A.T.G., A.T.V. en ander, het die A.T.K.V. ontstaan - gebore in die noodtydperk van die Afrikaner, gevorm deur enkele versiende leiers, voortgedra deur mense wat rigting gesoek het, wat in opstand gekom het teen onreg en wat in opstand gekom het teen onreg en wat as groep hulle wou laat geld vir hulle eie en ook ' $n$ reg van bestaan in hul Vaderland opgeëis het. Hulle besondere situasie en die status wat hulle as spoorwegmanne beklee het (of gebrek aan status), hulle samesyn in die werksituasie waar hulle mekaar leer ken het. die mate van afsondering wat hulle lot was, die gemis aan aanvaarding in die gemeenskap (wat ook weer historiese veroorsaking gehad het), die gevoel van lotsgebondenheid en miskien veral die besef dat hulle getalle aansienlik word en dus 'n krag kon wees, het hulle laat volhou met die aangevange taak.

Dit is onnodig vir ons doel om die verdere organisasiegeskiedenis, die stryd en terugslae, voorspoed en oorwinnings van die vereniging na te loop. Ons kan slegs meld dat die A.T.K.V. in ledetal gegroei het tot meer as 60,000 , dat sy bates toegeneem het en dat hy vaste staanplek in S.A. verower het. Om egter die vrae wat vroeër gestel is te kan beantwoord, is dit nodig om te kyk na sommige van die A.T.K.V. se prestasies en veral te let op sy doelstellings en hoe dit verwesenlik word. In die algemene drang tot selfverwesenliking, selfopheffing en selfbeskerming het die A.T.K.V. as kultuurorganisasie ontstaan onder lede van die spoorwegpersoneel. Al vegtende het hy voortbestaan en so bestaan hy nog voort omdat die noodsaak vir sy bestaan nog nie verdwyn het nie, omdat daar vir hom nog werk is. Kultuurwerk is positiewe bouwerk, en hierin het die vereniging sy taak reg waardeer en deur- 
gevoer. 'n Groep Afrikaners wat dit nie breed gehad het ten opsigte van wêreldse besittinge nie, wat in die gemeenskap 'n geringe plekkie beklee het, het deur inspanning en eie ontwikkeling die spoorweë verower; het in sy oorwinning teruggekeer tot die medespoorwegwerker en tot die volk op die terrein van blywende gesonde kultuurwerk. Uit nood gebore het die A.T.K.V., glo ons in beskeidenheid, weldoener geword op die volksterrein.

Die A.T.K.V. bepaal in sy grondwet dat die vereniging staan op Afrikaanse Christelik-historiese grondslag. Ook hierin skaar hy hom by sy voorgangers en tydgenote. Die hoofdoelstellings van die Vereniging bepaal o.a. dat hy die gebruik van Afrikaans binne en buite die Spoorwegdiens wil bevorder, die Afrikaanse kuns en kultuur bevorder, die intellektuele, kulturele en maatskaplike welsyn van sy lede bevorder, die bande van kameraadskap onder sy lede nouer aanhaal, en die belange van lede en hulle gesinne wil behartig, ens.

Die inleiding tot die A.T.K.V. se Akte van oprigting lui soos volg:

„Nademaal die Afrikaanse volk erken dat hy hier aan die skone suidpunt van Afrika as ' $n$ volk tot stand gekom het, en gevestig is op 'n eie bodem deur die wil van die Almagtige God, en dat hy nog hier in stand gehou word, word dit so beskou dat hierdie volk ook 'n taak het om sy spesifiek eie te handhaaf en uit te bou tot eer van God en tot veredeling van sy eie op die gebied van die taal en die kultuur met die erkenning van, waardering en agting vir die eiendomlike van elke ander bevolkingsgroep. So is dit ook dat die A.T.K.V. (S.A.S. en H.) glo dat hy in hierdie verband 'n taak het en daarom tot stand gekom het."

Hoe het die A.T.K.V. dan in die 39 jaar van sy bestaan hierdie belydenis uitgeleef en hoe het hy sy doelstellings nagestreef? Dit is nie moontlik om al die prestasies op te noem nie, maar dit mag ons veroorloof word om 'n paar hoogtepunte te noem.

In Augustus 1934 skryf die toenmalige hoofvoorsitter, mnr. H. J. Klopper, dat die stigting van die A.T.K.V. 'n plan was om 'n vereniging in die lewe te roep wat bokant tydelike of stoflike dinge staan, wat die beskermheer van ons taal en kultuur en geestesgoedere op die spoorweë sou word; wat die lid tot ' $n$ beter Afrikaner, ' $n$ beter vader of moeder, ' $n$ 
beter werknemer sal maak...

Hierdie laaste woorde sou vir die A.T.K.V. gedurende al die jare van sy bestaan van die allergrootste belang wees. By herhaling het dit in die werk van die Vereniging geblyk dat hy hom dit ten doel stel om sy lede met die adel van die arbeid te besiel. Ons kyk na 'n aanhaling uit mnr. Klopper se voorsittersrede in 1935:

„Ons wil ons lede besiel met die gedagte dat elke daad wat hulle doen 'n nasionale daad is, ten goede of ten kwade. Elke trein wat 'n drywer by die stasie op tyd inbring, is 'n nasionale daad wat ons nasionale waarde verhef..."

Deur middel van artikels in Die Taalgenoot, lesings, en die verspreiding van pamflette en deur voorbeeld en invloed is lede aangemoedig om ' $n$ waardige arbeidsbeskouing te kweek en uit te lewe en so die Goddelike opdrag aan die mens te vervul; om die nederigste spoorwegwerk te verhef tot iets mooi en edel.

Die A.T.K.V. het van die beginjare af sy arbeidsveld breër gesien as net die spoorweë. Dit was sy uitgangspunt en sy doel om die spoorwegman 'n eerbare plek te laat inneem in die gemeenskapslewe en om die mate van afsondering wat bestaan het, af te breek. Daarom dan dat die A.T.K.V. die hele Afrikaanse kultuurlewe bestryk het.

In 1931 reeds verskyn die eerste uitgawe van Die Taalgenoot met die voorgestelde doel om as spreekbuis van die Vereniging die amptelike beskouing te propageer, om kulturele en ander opvoedingswerk te verrig en om inligting omtrent die Vereniging te bestry. Die Taalgenoot gaan steeds ononderbroke voort met hierdie werk. Die Vereniging besit vandag twee vakansieoorde, 'n sterftefonds, 'n hoofkantoorgebou, 'n studiefonds ens. Die A.T.K.V. het die Suid-Afrikaanse Noodhulpliga gestig, die Simboliese Ossewatrek van 1939 georganiseer en met ander volksfeeste meegehelp. Deur sy vroue-organisasie, die Vrou- en Moederbeweging, is die Voortrekkermuurtapiserieë versorg. Die dames het ook 'n Kinderstrandhuis by Hartenbos opgerig. Die Rapportryersorganisasie het sy ontstaan gehad as gevolg van die A.T.K.V. se rapportryersfeeste in 1949. In 1966 het die A.T.K.V. 'n bydrae gelewer tot die stigting van 'n leerstoel in Afrikaanse Volks- en Kultuurkunde aan die Universiteit van Stellenbosch. Daar is nog veel meer, maar ons volstaan hiermee. 
As kultuurorganisasie het die A.T.K.V. veel verrig en ons glo sodanige bydrae gelewer dat Afrikaans op die spoorweë 'n waardige plek kon inneem. Sodoende het die Afrikaanse spoorwegman ook tot sy reg gekom in die diens en daarbuite. Wat egter veel dieper gaan as taalberegting en -erkenning is seker die feit dat die spoorwegman die vreemde spoorwegstelsel wat uit die buiteland na S.A. gekom het, stilweg positief beïnvloed het om nader na 'n eie Suid-Afrikaanse instelling te vorder, met ander woorde daar is begin om 'n Afrikaanse vervoerkultuur te skep. Hierdie taak is egter nog op verre na nie voltooi nie en daarvan is die A.T.K.V. terdeë bewus en streef hy steeds daarna om in sy toekomstake voorsiening te maak vir uitbreiding van hierdie en ander kerngedagtes. Benewens die algemene kultuurwerk en take soos taalhandhawing, die bevordering van kunste soos die letterkunde, musiek, toneel, e.a. waarmee die A.T.K.V. hom besig hou, sien die Vereniging vir hom 'n spesifiek eie taak in die beroepsverband waarin sy lede staan, 'n taak wat net deur lede self gedoen kan word.

Ten spyte van aansienlike vordering wat gemaak is, is daar nogtans ' $n$ baie duidelike besef dat groot werk nog voor lê. Voortspruitend hieruit, lê die take enersyds op die breë volksakker en andersyds by die begrensde beroepsterrein. In hierdie verband kan ons noem die opvoedingswerk ten opsigte van die arbeidsbeskouing van ons mense en daarmee saam die handhawing van taal en kultuur in die werk. Wat laasgenoemde betref, dink ons dadelik aan die geweldige agterstand wat nog bestaan op die gebied van die vaktaal, nie slegs omdat daar nie reeds geweldig baie gedoen is nie, maar eerder omdat so baie nog gedoen moet word, en ook, miskien veral, omdat die gebruik van dit wat reeds bestaan, veel te wense laat. Woordelyste en boeke bestaan, maar word nie oral algemeen in die praktyk gebruik nie. Dár veral het die A.T.K.V. vandag vir hom weer 'n taak gesien.

Seker een van die mooiste prestasies van die A.T.K.V. is die feit dat daar binne die geledere van die groter Vereniging 'n organisasie vir dames geskep is waarin hulle hul eie (en ons) sake behartig. Die Vrou- en Moederbeweging het reeds groot werk verrig en is steeds besig met kultuurtake in die breë sin van daardie woord; dus nie net liefdadigheidswerk of daardie soort van sleurwerk wat dikwels ten onregte aan 
vroue-organisasies toegedig word nie.

Dat A.T.K.V. sy bestaan geregverdig het, word verder beklemtoon deur die feit dat soortgelyke organisasies gestig is deur die personeel van die departement Pos- en Telegraafwese, die Suid-Afrikaanse Polisie en die Weermag. Elkeen van hierdie verenigings het al in eie kring en daarbuite mooi en gewaardeerde werk verrig en gaan van $\mathrm{krag}$ tot $\mathrm{krag}$. A.T.K.B. neem 'n reuse-aandeel in die beoogde oprigting van die Afrikaanse Taalmonument in 1975, A.K.V.V. het die verantwoordelikheid gedra vir die daarstelling van die Louis Trichardgedenktuin in Lourenco Marques, Akpol beoog om vir die lede van die Z.A.R.P. wat tydens die Tweede Vryheidsoorlog na 'n heroïse stryd op Bergendal (naby Belfast) gesneuwel het, 'n monument op te rig. Dit is nie naasteby alles wat hierdie verenigings gedoen het nie, maar soos die A.T.K.V. beywer hulle hul vir taalhandhawing, bevordering van die kuns en kultuur en die opbou van hulle lede.

Hierdie kultuurverenigings binne beroepsverband het die geleenthede wat bestaan op voortreflike wyse benut. Mense in die arbeid tree in gemeenskap met medemense wat die geleentheid skep vir verskeie soorte groepoptrede en dit was inderdaad ' $n$ blink ingewing om ook 'n kultuurorganisasie in beroepsverband tot stand te bring. Omdat hierdie organisasies op Christelik-nasionale grondslag staan kan hulle 'n betekenisvolle bydrae tot die vorming van die Afrikanervolk op vaste fondament lewer. Omdat hulle mense vanweë hulle beroepsverband in so 'n atmosfeer kan saamsnoer, is dit moontlik om die arbeid in die regte Calvinistiese perspektief te bevorder, om by die arbeider sy eerste verantwoordelikheid, $\mathrm{nl}$. die teenoor God, tuis te bring, om hom te laat besef dat arbeid roeping van God is en dat dit 'n Goddelike kultuuropdrag aan die mens is.

Hiermee het ons ook die vraag beantwoord of uitbreiding van die gedagte na ander beroepsgroepe aan te beveel en bevorderlik sal wees. Die bestaande organisasies het nie geslaag omdat dit juis die S.A. Polisie, die Weermag of die S.A. Spoorweë was wat daarmee voortgegaan het nie, maar omdat dit mense binne dieselfde beroepsgroep was. Eweneens kan sulke organisasies slaag in watter werkkring hul ook al aangepak word. Trouens, die geleentheid lê en wag en eintlik is dit 'n jammerte dat dit nie benut word nie. Die moontlikheid wat 
bestaan is unlangs weer so treffend geilllustreer toe die Federale Mynbou/General Mining-groep 'n boekie met 'n basiese tweetalige mynbouwoordeskat aan mynwerkers beskikbaar gestel het. Omdat beweer is dat Afrikaanse mynbouterme nie beskikbaar is nie, is die algemeenste terme saamgevat en in 'n gerieflike formaat beskikbaar gestel. Dr. T. F. Muller, die bestuderende direkteur van die groep, sê in 'n referaat gelewer voor die Vaktaalkongres van die Akademie op 27 Oktober 1967, dat die kern van die probleem nou is, nie net om op akademiese grondslag te werk aan die bou van terme nie, maar om toegang tot die mynwerker te kry en sy aktiewe medewerking te verwerf, eerstens vir die aanvaarding van dit wat reeds bereik is en tweedens vir die gesamentlike bouwerk wat nog gedoen moet word. Ons kan ons geen beter metode voorstel om dit reg te kry as om 'n organisasie te stig van mynwerkers wat hulle o.a. daarvoor sal beywer om die Afrikaanse mynbouvakterme te bevorder nie en, siedaar, 'n kultuurorganisasie van mynwerkers!

Beroepsgroepe kan organisasies op die been bring wat hulle in allerlei rigtings tot voordeel van die lede beywer en kan, soos bewys is, ook die kultuurterrein betree. Benewens ander kultuurtake kan sodanige kultuurverenigings hulle daarop toespits om daardie arbeidsterrein te verower, om dit ' $n$ eie, mag ons sê Suid-Afrikaanse, inslag en kleur te gee, maar veral om ten opsigte van arbeidsbeskouing 'n positiewe heilsame invloed uit te oefen. Daarin hoofsaaklik vind ons rede en behoefte vir die bestaan en werk vir sulke organisasies. Dr. Verwoerd het in 1962 aan die A.T.K.V. gesê dat die Republiek van Suid-Afrika nou tot stand gekom het en dat dit die taak van die volk is om daaraan inhoud en betekenis te gee op alle terreine. Die arbeid is een van die belangrikste terreine wat in gedagte kom. Dit is 'n spesifieke taak wat ten beste deur die mense in die beroep self vervul kan word.

Dit word geensins bepleit dat alle beroepsgroepe hulle in afgeslote kultuurorganisasies moet afsonder van die res van die gemeenskap en daarmee die gevaar loop om klasseverdeling te bevorder nie. Die kultuur van ' $n$ volk betrek almal, en die bestaande kultuurorganisasies vind mekaar voortdurend op gemeenskaplike terrein. Die F.A.K. vervul hierin ook ' $n$ waardevolle werk deur alle verenigings saam te bind en die gevaar van afgesonderheid is nie wesenlik nie. Die S.A. 
Spoorweë se personeel bestaan uit 'n wye verskeidenheid van grade wat verskillende soorte werk verrig. Daar is administratiewe werkers, ambagsmanne, ingenieurs ens. en juis hierin bestaan 'n gevaar van klassevorming. Die A.T.K.V. betrek egter die laaimeester, die klerk, die ambagsman, die toesighouer ens. almal saam op gelyke vlak in sy kultuurwerk en lewer dan juis 'n bydrae om klasseverskille uit te wis. Die A.T.K.V. is verder juis ook 'n kanaal om die publiek en die spoorwegpersoneel bymekaar te bring.

Ten slotte, wat die toekomsaksie van hierdie kultuurverenigings betref, moet hulle steeds let op die behoeftes wat bestaan, let op die doodloopspore van verstarring, bewus wees van die dwaalspore wat tot vervreemding kan lei en dan ook die uitdagings van die huidige tydstip aanvaar. Daar moet kennis geneem word van die waarskuwende stemme wat opgaan en daar moet voortdurend selfondersoek wees om te bepaal of die rigting nog suiwer is en of daar nog op vaste fondament gebou word. In hierdie verband clink ons aan twee groot beginsels wat voortdurend onder oë gesien moet word, nl. (a) dat die arbeid reg gesien en waardeer word as 'n roeping van God en (b) dat die klem in die term "Christeliknasionaal" wat ons almal met soveel oortuiging in ons doelstellings opneem, steeds sal val op "Christelik" en dat dit nie ' $n$ holle frase word of dat die klem verskuif na "Nasionaal" en die Christelik slegs behoue bly om ons gewetes te salf nie.

M. van Vuuren.

Florida. 